\title{
Enhancement of Diffusion Assisted Bonding of the Bimetal Composite of Austenitic/Ferric Steels via Intrinsic Interlayers
}

\author{
Chenwei He ${ }^{1}$, Guangshan Pan ${ }^{2}$, Lu Xie ${ }^{3, *(D)}$ and Qing Peng ${ }^{4,5, *(D)}$ \\ 1 Reactor Engineering and Safety Research Center, China Nuclear Power Technology Research Institute Co Ltd., \\ Shenzhen 518031, China; hechenwei@cgnpc.com.cn \\ 2 China Ship Scientific Research Center, Wuxi 214082, China; panguangshan@163.com \\ 3 School of Mechanical Engineering, University of Science and Technology Beijing, Beijing 100083, China \\ 4 Physics Department, King Fahd University of Petroleum \& Minerals, Dhahran 31261, Saudi Arabia \\ 5 K.A.CARE Energy Research \& Innovation Center at Dhahran, Dhahran 31261, Saudi Arabia \\ * Correspondence: xielu@ustb.edu.cn (L.X.); qing.peng@kfupm.edu.sa (Q.P.)
}

Citation: He, C.; Pan, G.; Xie, L.; Peng, Q. Enhancement of Diffusion Assisted Bonding of the Bimetal Composite of Austenitic/Ferric Steels via Intrinsic Interlayers. Materials 2021, 14, 2416. https://doi.org/ $10.3390 /$ ma14092416

Academic Editor: Julia A. Baimova

Received: 18 March 2021

Accepted: 28 April 2021

Published: 6 May 2021

Publisher's Note: MDPI stays neutral with regard to jurisdictional claims in published maps and institutional affiliations.

Copyright: (c) 2021 by the authors. Licensee MDPI, Basel, Switzerland. This article is an open access article distributed under the terms and conditions of the Creative Commons Attribution (CC BY) license (https:// creativecommons.org/licenses/by/ $4.0 /)$.

\begin{abstract}
We investigate the effect of the intrinsic interlayers on the diffusion assisted bonding properties of the austenitic steel (stainless steel 316L) and ferric steels (Low-carbon steel Q345R) in a hot rolling process by molecular dynamics simulations and experiment. The introduction of an intrinsic interlayer ( $\mathrm{Cr}$ or $\mathrm{Ni}$ ) widens the diffusion region, leading to enhancement of bonding. The thickness of the diffusion region enlarges with an increase of temperature, with an enhancement factor of $195 \%$ and $108 \%$, for $\mathrm{Cr}$ and $\mathrm{Ni}$ interlayer, respectively, at the temperature of $1800 \mathrm{~K}$. Further diffusion analysis reveals the unsymmetrical diffusion near the interface. Our experimental investigation evidenced our computation discovery.
\end{abstract}

Keywords: molecular dynamics simulation; intrinsic interlayers; diffusion bonding; hot-pressing process

\section{Introduction}

Bimetallic composites are important with broad applications in machinery, aerospace, power and electronics industries because of their superior properties. However, their quality and properties are significantly influenced by the microstructure and strength of the interfaces. There are some shortcomings in the interfaces of bimetallic composites, such as easy oxidation of the interface, creation and formation of brittle intermetallic at the interface and creation and propagation of micro cracks, which results in reducing remarkably the bonding strength of the interface. For example, some researches find that because the solubility of the elements of $\mathrm{Fe}, \mathrm{Ti}, \mathrm{Cr}$ and $\mathrm{Ni}$ will be severely limited in the solid state, brittle intermetallics like $\mathrm{Fe}_{2} \mathrm{Ti}, \mathrm{FeTi}, \mathrm{Cr}_{2} \mathrm{Ti}$ and $\mathrm{Fe}_{2} \mathrm{Ti}_{4} \mathrm{O}$ are formed in the interface [1-5]. In addition, because the alloying species have different intrinsic diffusion coefficients, the bimetals will create and propagate the micro cracks in the interface, which seriously affect the physical and mechanical properties [6,7]. Since the preparation process of hot roll-cladding plates is conducted at a high temperature, the bonding interface is easily oxidized, which results in remarkably reducing the bonding strength of the interface $[8,9]$. Hence, the key point of the research on the bimetal composite is how to improve its overall mechanical properties.

Studies have shown that the addition of intermediate interlayers on the interface with certain plasticities, strengths and affinities can improve the bonding properties of bimetal composite panels [10-18]. For example, detailed mechanical testing and metallurgical examinations were carried out to investigate the friction welding between TiNi alloy and austenitic stainless steel with an Ni interlayer [15]. The results indicate that due to the addition of the $\mathrm{Ni}$ interlayer the brittle intermetallic $\left(\mathrm{Fe}_{2} \mathrm{Ti}\right)$ will be drastically reduced and the mechanical property of the bimetal composite will be effectively improved, see 
Fukumoto et al. [15]. The tensile strengths of the interfaces of $\mathrm{Nb} /$ sapphire composites with and without $\mathrm{Cr}$ interlayers have been measured by a modified laser spallation experiment. The results show that the addition of a $\mathrm{Cr}$ interlayer will increase the tensile strength of the interface of $\mathrm{Nb} /$ sapphire composites, see Yuan et al. [17]. Despite extensive efforts by both experimental [19-21] and numerical methods [22-26], the effect mechanism of the intermediate interlayer on the bonding interface is still lacking. Such a mechanism is useful in the prediction and design of the bonding strength for the interface and helpful in optimizing the manufacturing process of bimetal composites.

Diffusion bonding is a solid-state bonding process with good mechanical and metallurgical bonding properties in the bonding area, so it is an attractive manufacturing method for aerospace applications. [27]. Ding et al. [28] used the vacuum solid-state diffusion method to combine copper and titanium on the $\mathrm{CoCrFeMnNi} \mathrm{high-entropy} \mathrm{alloy} \mathrm{intermediate}$ layer, and investigated the influence of temperature on the diffusion reaction mechanism. Their research shows that the effective diffusion barrier layer of the combination of $\mathrm{Cu} / \mathrm{Ti}$ dissimilar materials can use $\mathrm{CoCrFeMnNi}$ high-entropy alloy. Liu et al. [29] achieved good bonding between $\mathrm{CoCrFeMnNi}$ high entropy alloy and pure $\mathrm{Cu}$ at temperatures of $750 \sim 850{ }^{\circ} \mathrm{C}$ by solid-state diffusion method. The results show that $\mathrm{Cu}$ atoms diffuse into the high-entropy alloy lattice more easily. With the increase of temperature, the diffusion degree of the high-entropy alloy components towards the $\mathrm{Cu}$ side decreases in the order of $\mathrm{Mn}>\mathrm{Cr}>\mathrm{Fe}>\mathrm{Co}>\mathrm{Ni}$. Negemiya et al. [30] investigated the influence of the diffusion bonding process parameters of AISI 410 martensitic stainless steel and nickel [Su 718]-based superalloy. From this study, it was found that the tensile strength and hardness of the joint manufactured at a bonding temperature of $980^{\circ} \mathrm{C}$, a bonding pressure of $16 \mathrm{MPa}$ and a holding time of $75 \mathrm{~min}$ were $263 \mathrm{MPa}$ and $450 \mathrm{HV}$.

The molecular dynamics simulation method has been used to study the mechanical properties of materials at the atomic scale by many scholars [31-39]. For example, the mechanical properties of a single metal under the tensile or compressive process have been extensively studied [40-43]. The atomic structure and mechanical and thermodynamic stability of the vacancy clusters of $\mathrm{Cu}$ under a uniaxial and volumetric tensile strain was examined by means of atomistic simulations by Peng et al. [44] and the nanoindentation on monocrystalline and nanotwinned $\mathrm{Ta}$ (nt-Ta) films were performed by means of molecular dynamics simulations by Huang et al. [45]. Besides single crystal, MD studies have been conducted on the interfaces of bimetallic composites in nanometer scale [46-54]. The interfacial tension strength was associated with pertinent characteristics of the interface structure in order to illustrate the impact of interfacial porosity and stresses acting on the slip-plane in non-glide directions on tensile strength of the interface and a model was proposed on the interface strength, see Douglas et al. [48]. They found that the interface is critical for mediating deformation mechanisms and mechanical properties. Weissmann et al. investigated the process of amorphization on the interface of the $\mathrm{Co}-\mathrm{Zr}$ system where the degree of amorphization increased with the temperature [55]. Chen et al. investigated the atomic diffusion behavior in the process of explosive welding on the $\mathrm{Cu}-\mathrm{Al}$ system and found that the atomic diffusion mainly occurred in the process of the explosive welding [56]. Chen et al. was the first to reveal that the dynamic evolution of the patterns of misfit dislocation in the interface appears in some specific types of the interface and loading schemes, which made great contributions to the mechanism of the dislocation nucleation and shear sliding [57].

Despite the extensive studies on crystals including single crystals and bi-crystals, there are few researches on bi-metal composite at the atomistic scale due to its complexities. It would be advantageous to study the composite of austenitic steel and ferritic for the combination advantages of corrosion-resistance, high strength and low price. In our previous work, the mechanics of the atomic diffusivity on the interface between bulk austenitic steel and carbon steel have been studied by using molecular dynamics simulations. However, the physical metallurgical mechanisms related to the effect of the intermediate interlayer are still elusive. 
In this work, we aim to investigate the effect of an intermediate interlayer on the bonding of the interface between austenitic steel and carbon steel during the process under hot compression. Due to the outstanding corrosion resistance and broad applications of the 316L stainless steel including in chemicals, the petrochemical industry, marine applications, wastewater treatment, medical devices and more, the stainless steel (316L) was selected as our research material. In addition, the effect of some important elements in 316L stainless steel, such as $\mathrm{Ni}$ and $\mathrm{Cr}$, on the interfacial bonding properties, was examined. The $\mathrm{Fe}_{74} \mathrm{Cr}_{16} \mathrm{Ni}_{10}$ alloy is used to model the 316L stainless steel by keeping the most important components (Fe, $\mathrm{Cr}$ and $\mathrm{Ni}$ ) in proper concentration, as in our previous research. The reason to ignore the minor compositions is that their low concentration results in a trivial effect on the mechanical properties, as detailed in Supplementary Information. The pure Fe metal is used to model the carbon steel (Q345R) because the content of iron is over 98\%. The intrinsic interlayers refer to the interlayers formed by the intrinsic elements- $\mathrm{Fe}, \mathrm{Cr}$ and Ni here. The choice of these intrinsic interlayers is due to the convenience and the availability of the inter-atomic potentials. The focus of this study is the effect of the intrinsic intermediate interlayers of $\mathrm{Cr}$, $\mathrm{Ni}$ and $\mathrm{Fe}$ on the interfacial diffusion and compression mechanism, which has been comprehensively studied using a $\mathrm{FeCr}_{16} \mathrm{Ni}_{10} / \mathrm{Fe}$ model.

\section{Simulation Details}

Molecular dynamics simulation was used to study the effect of the intrinsic interlayer on the diffusion bonding of the austenitic steel and ferric steel. The atomic interactions are formulated using the empirical embedded atom method (EAM) potential [58,59]. The initial model of $\mathrm{FeCr}_{16} \mathrm{Ni}_{10} / \mathrm{Fe}$ composite is shown in Figure 1a. The models of both Fe metal and $\mathrm{FeCr}_{16} \mathrm{Ni}_{10}$ alloy are put together inside a simulation box whose dimension is $13.5(X) \times 13.5(Y) \times 27(Z) \mathrm{nm}^{3}$. The contact surface between Fe metal and $\mathrm{FeCr}_{16} \mathrm{Ni}_{10}$ alloy is the plane ( $\begin{array}{ll}0 & 0\end{array}$ ). There are 355,023 atoms in the model of the $\mathrm{FeCr}_{16} \mathrm{Ni}_{10} / \mathrm{Fe}$ composite, 172,773 atoms in the areas of Fe metal and 182,250 atoms in the areas of $\mathrm{FeCr}_{16} \mathrm{Ni}_{10}$ alloy. The initial model of $\mathrm{Fe} / \mathrm{Ni} / \mathrm{FeCr}_{16} \mathrm{Ni}_{10}$ composite is shown in Figure $1 \mathrm{~b}$. The Ni interlayer is put inside a simulation box whose dimension is $13.5(X) \times 13.5(Y) \times 1.7(Z) \mathrm{nm}^{3}$, which contains 25,920 atoms. The initial model of $\mathrm{Fe} / \mathrm{Cr} / \mathrm{FeCr}_{16} \mathrm{Ni}_{10}$ is shown in Figure 1c. The $\mathrm{Cr}$ interlayer which contains 28,350 atoms is put inside a simulation box whose dimensions are $13.5(X) \times 13.5(Y) \times 13.5(Z) \mathrm{nm}^{3}$. All molecular dynamics simulations are carried out by the Large-scale Atomic/Molecular Massively Parallel Simulator (LAMMPS) [60] and post-processing the atomistic data obtained from MD simulation is performed by the Open Visualization Tool (OVITO) [61].

The models along the $x$ and $y$ directions set the periodic boundary conditions. The velocity-Verlet algorithm is implemented to calculate the motion equation of the atoms in the simulation system with a constant time step $\left(1 \times 10^{-15} \mathrm{~s}\right)$ [62]. Before loading compression, the systems are relaxed sufficiently using a Nose-Hoover thermostat and a Nose/Hoover pressure barostat to ensure the combination of the $\mathrm{FeCr}_{16} \mathrm{Ni}_{10}$ alloy and Fe metal at high temperature $[63,64]$. The systems are kept at a pressure of zero bar and a constant temperature $(\mathrm{T}=1500 \mathrm{~K})$ for $100 \mathrm{ps}$. After relaxation, compression along the $\mathrm{z}$ direction is subsequently applied to the models at a temperature $(1500 \mathrm{~K})$ and a strain rate $\left(3 \times 10^{9} \mathrm{~s}^{-1}\right)$. The relatively short time scale and the insufficient geometric scale are the limitations of molecular dynamics. Therefore, compared with actual experiments, the strain rate obtained by molecular dynamics is much higher. Since molecular dynamics is explained from the micro and nano scale, it is necessary to simplify the unimportant parameters in the experimental process. Therefore, diffusion can also be studied at high strain rates. An isobaric-isothermal (NPT) ensemble is used to keep the pressure of zero in the directions of $x$ and $y$ during the uniaxial compression. Twelve groups of simulations have been performed to manifest the mechanism on how the intrinsic interlayer affects the process of compression and interfacial diffusion. These models applied uniaxial compression at a constant strain rate $\left(3 \times 10^{9} \mathrm{~s}^{-1}\right)$ with four temperatures $(1500 \mathrm{~K}, 1600 \mathrm{~K}$, $1700 \mathrm{~K}$ and $1800 \mathrm{~K}$ ), which were selected because of the compromise of high diffusivity 
and melting point. Only if the temperature reaches adequate levels between $0.6-0.8 \mathrm{~T}_{\mathrm{m}}$ (where $\mathrm{T}_{\mathrm{m}}$ represents the melting points of the materials involved) [18,65], can the atoms of the materials on both sides diffuse each other. Since the melting point of Fe metal and $\mathrm{FeCr}_{16} \mathrm{Ni}_{10}$ alloy are $1868 \mathrm{~K}$ and $2123 \mathrm{~K}$ respectively [66], the temperature levels $1500 \mathrm{~K}$, $1600 \mathrm{~K}, 1700 \mathrm{~K}$ and $1800 \mathrm{~K}$ are selected in this work.
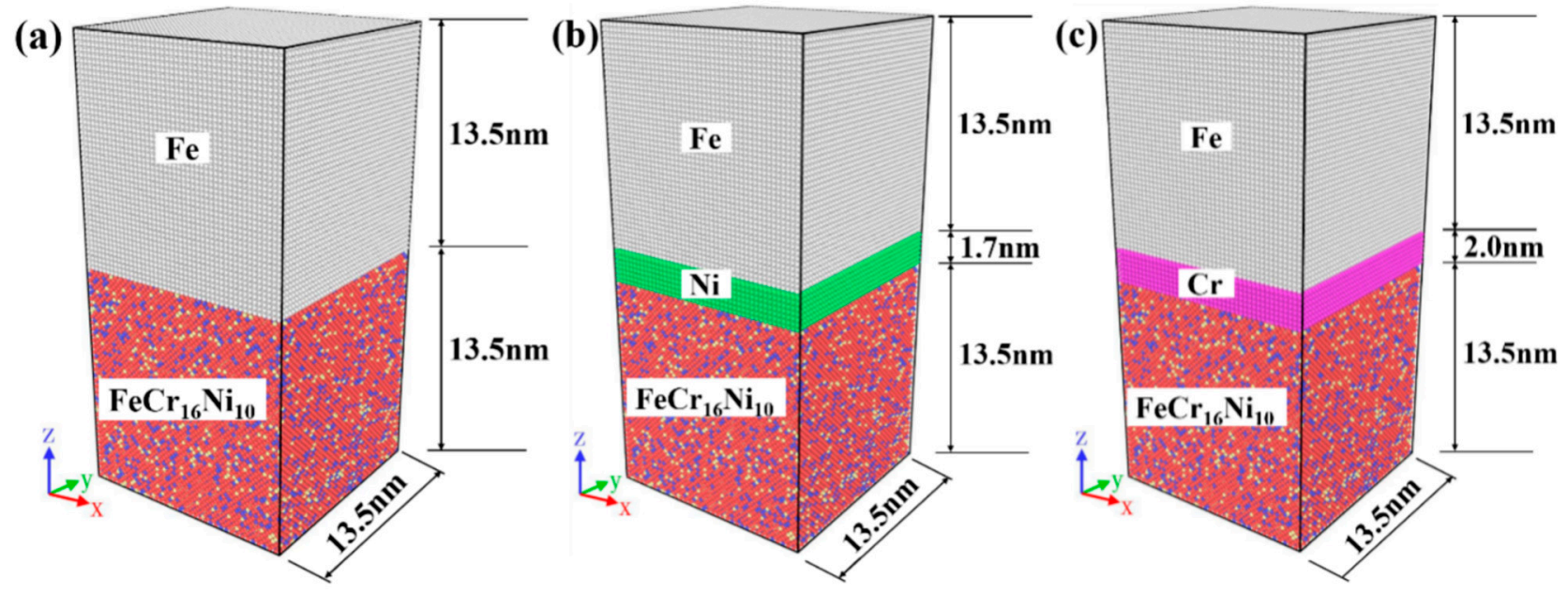

Figure 1. Initialization model of (a) $\mathrm{Fe} / \mathrm{FeCr}_{16} \mathrm{Ni}_{10}$ as pristine configuration; (b) $\mathrm{Fe} / \mathrm{Ni} / \mathrm{FeCr}_{16} \mathrm{Ni}_{10}$ as Ni-layer configuration; and (c) $\mathrm{Fe} / \mathrm{Cr} / \mathrm{FeCr}_{16} \mathrm{Ni}_{10}$ as $\mathrm{Cr}$-layer configuration. (The atom layer of Fe metal is on the top of model and the atom layer of $\mathrm{FeCr}_{16} \mathrm{Ni}_{10}$ alloy is on the bottom of model. $\odot$ : Fe atoms in the atom layer of Fe metal, $\bullet$ : Fe atoms in the atom layer of $\mathrm{FeCr}_{16} \mathrm{Ni}_{10}$ alloy, $\mathrm{O}$ : Cr atoms in the atom layer of $\mathrm{FeCr}_{16} \mathrm{Ni}_{10}$ alloy, $\odot$ : Ni atoms in the atom layer of $\mathrm{FeCr}_{16} \mathrm{Ni}_{10}$ alloy, $\odot$ : $\mathrm{Ni}$ atoms in the Ni interlayer, $\bullet$ : $\mathrm{Cr}$ atoms in the $\mathrm{Cr}$ interlayer).

\section{Results and Discussion}

\subsection{Stress-Strain Relationship}

To investigate the effect of the intrinsic interlayer on the hot rolling process, the $\mathrm{FeCr}_{16} \mathrm{Ni}_{10} / \mathrm{Fe}$ models with and without the Ni layer (Cr layer) were conducted to simulate the hot rolling process. The stress-strain curves obtained by simulating a hot rolling process of $\mathrm{FeCr}_{16} \mathrm{Ni}_{10} / \mathrm{Fe}$ composites with different intrinsic interlayers at the temperatures of $1500 \mathrm{~K}, 1600 \mathrm{~K}, 1700 \mathrm{~K}$ and $1800 \mathrm{~K}$ are illustrated in Figure 2. Since the coherent interface between the $\mathrm{FeCr}_{16} \mathrm{Ni}_{10}$ alloy and Fe metal will lead to the lattice mismatch [67-69], all stresses fluctuate around zero at the initial stage. Then the further plastic deformation will require a greater compressive stress. The stress-strain curves show a drastic rise as the strain reaches a certain value in the cases (i.e., pristine, Ni-layer and Cr-layer) at different temperature ranges. After the value of stress increases to the maximum, the stress drops rapidly. Then, the interface exhibits the progressive plastic deformation in which the flow stress gradually decreases with increasing strain. According to three-stage theory on the compounding process of the hot rolled sheet, the rough surface deforms under stress loading, which increases the contact area and then two metals in contact with each other produce a coordinated plastic deformation. The bonding difficulty of a bimetallic clad plate is measured by its maximum stress during the deformation process [70]. 

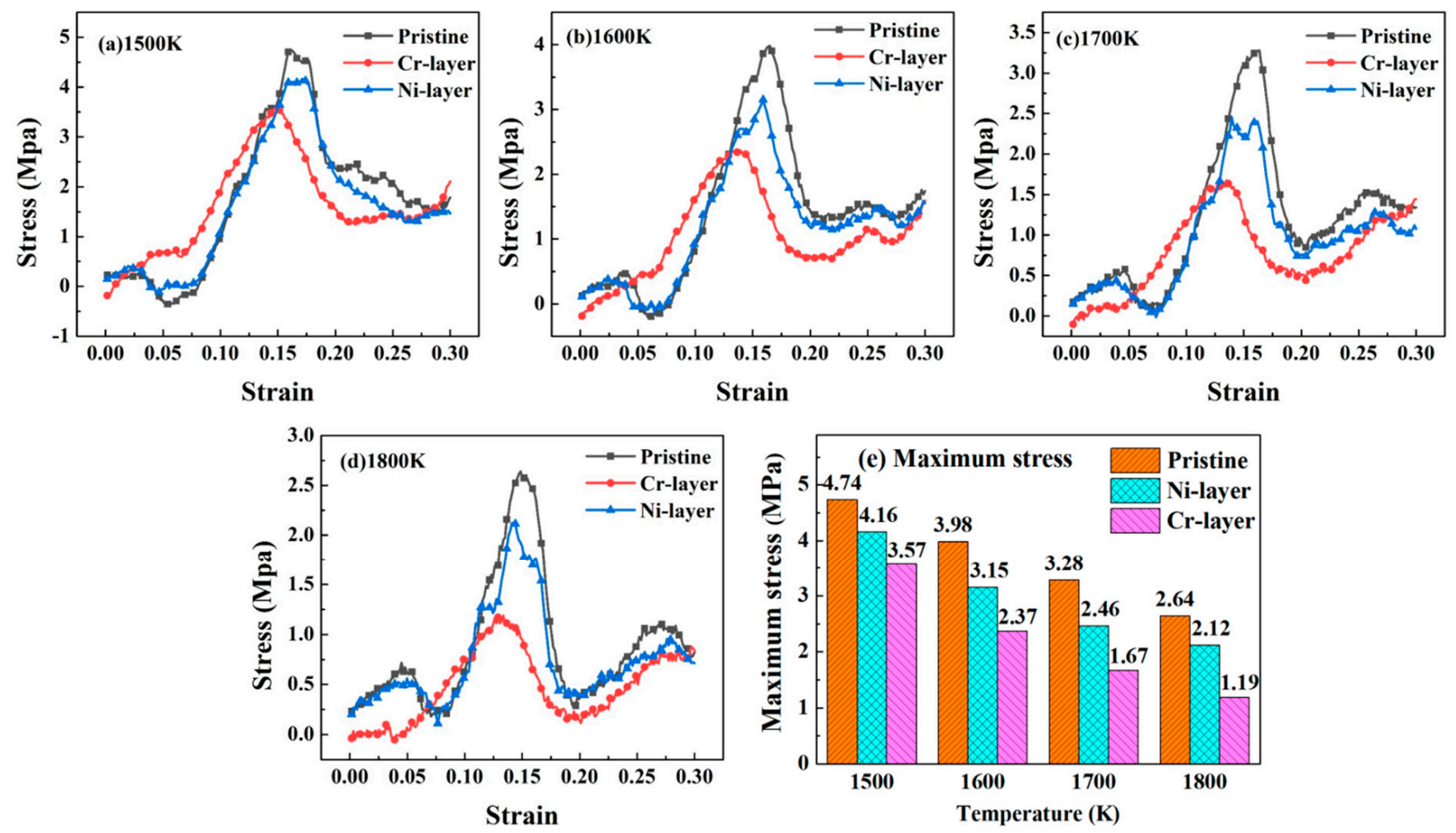

Figure 2. Stress-strain curves of the $\mathrm{FeCr}_{16} \mathrm{Ni}_{10} / \mathrm{Fe}$ composites with different intrinsic interlayer at various temperature: (a) $1500 \mathrm{~K}$; (b) $1600 \mathrm{~K}$; (c) $1700 \mathrm{~K}$; (d) $1800 \mathrm{~K}$, (e) The maximum stress at four temperature.

At the temperature of $1500 \mathrm{~K}$, the maximum stress of the $\mathrm{FeCr}_{16} \mathrm{Ni}_{10} / \mathrm{Fe}$ composite is $4.74 \mathrm{MPa}$ when there is no intrinsic interlayer, namely pristine configuration. The maximum stress of the $\mathrm{FeCr}_{16} \mathrm{Ni}_{10} / \mathrm{Fe}$ composite reduces by $12.2 \%$ when the Ni intrinsic interlayer is present, namely Ni-layer configuration. Meanwhile, the maximum stress of the $\mathrm{FeCr}_{16} \mathrm{Ni}_{10} / \mathrm{Fe}$ composite reduces by $24.7 \%$ when the $\mathrm{Cr}$ intrinsic interlayer is present, namely $\mathrm{Cr}$-layer configuration. At the temperature of $1600 \mathrm{~K}$, compared with the $\mathrm{FeCr}_{16} \mathrm{Ni}_{10} / \mathrm{Fe}$ composite without intrinsic interlayer, the maximum stress of the $\mathrm{FeCr}_{16} \mathrm{Ni}_{10} / \mathrm{Fe}$ composite reduces by $20.7 \%$ with Ni-layer configuration. Meanwhile, the maximum stress of the $\mathrm{FeCr}_{16} \mathrm{Ni}_{10} / \mathrm{Fe}$ composite reduces by $40.3 \%$ with $\mathrm{Cr}$-layer configuration. At the temperature of $1700 \mathrm{~K}$, compared with the $\mathrm{FeCr}_{16} \mathrm{Ni}_{10} / \mathrm{Fe}$ composite without intrinsic interlayer, the maximum stresses of the $\mathrm{FeCr}_{16} \mathrm{Ni}_{10} / \mathrm{Fe}$ composite with the Ni-layer and Cr-layer reduce by $24.8 \%$ and $48.9 \%$, respectively. At the temperature of $1800 \mathrm{~K}$, compared with the $\mathrm{FeCr}_{16} \mathrm{Ni}_{10} / \mathrm{Fe}$ composite without intrinsic interlayer, the maximum stresses of the $\mathrm{FeCr}_{16} \mathrm{Ni}_{10} / \mathrm{Fe}$ composite with the Ni-layer and $\mathrm{Cr}$-layer reduce by $29.7 \%$ and $54.9 \%$, respectively. Obviously, the addition of the intrinsic interlayer reduces the maximum stress of the $\mathrm{FeCr}_{16} \mathrm{Ni}_{10} / \mathrm{Fe}$ composite on the hot rolling process and the addition of the $\mathrm{Cr}$ layer is more obvious than the addition of the Ni layer. So, the addition of the intrinsic interlayer can reduce the stress of bonding of the austenitic/ferric steels and is conducive to the hot rolling process of the bimetallic composites.

\subsection{Diffusion Bonding of the $\mathrm{FeCr}_{16} \mathrm{Ni}_{10} / \mathrm{Fe}$ Models during the Hot Rolling}

Only if the atomic concentrations of both $\mathrm{FeCr}_{16} \mathrm{Ni}_{10}$ alloy and $\mathrm{Fe}$ metal along the compression direction are more than $5 \%$, the region of the model of the $\mathrm{FeCr}_{16} \mathrm{Ni}_{10} / \mathrm{Fe}$ composite involved is defined as the diffusion region $[56,65]$. The atomic diffusion near the interfaces of the $\mathrm{FeCr}_{16} \mathrm{Ni}_{10} / \mathrm{Fe}$ composite during the hot rolling process has been observed and the atomic concentration distributions of the $\mathrm{FeCr}_{16} \mathrm{Ni}_{10} / \mathrm{Fe}$ composite with different intrinsic interlayers along the $Z$ direction at the temperature of $1800 \mathrm{~K}$ are illustrated in Figure 3. The atomic concentration distributions at the temperatures $1500 \mathrm{~K}, 1600 \mathrm{~K}$ 
and $1700 \mathrm{~K}$ are also illustrated, which are detailed in Supplementary Information. In addition, the snapshots of the model at a strain of 0.3 are also shown. The thickness of the diffusion region of the $\mathrm{FeCr}_{16} \mathrm{Ni}_{10} / \mathrm{Fe}$ composite without the intrinsic interlayer is $18.5 \AA$. However, the thickness increases by $108.1 \%$ when the Ni interlayer is added. Obviously, the Ni interlayer promotes the diffusion and combination of $\mathrm{FeCr}_{16} \mathrm{Ni}_{10}$ alloy and Fe metal. And good agreement was obtained when comparing our simulations with previous works. For example, the tungsten/ferric composite with a nickel interlayer which is applied to nuclear components is prepared by a diffusion bonding process and the result indicates a good diffusion bonding was obtained between the interfaces of both tungsten/nickel and nickel/ferritic by metallographic analysis [71]. It has also been observed from Figure $3 \mathrm{~b}$. that the atoms in the Ni intrinsic interlayer diffuse farther towards the layer of $\mathrm{Fe}$ metal than towards the layer of $\mathrm{FeCr}_{16} \mathrm{Ni}_{10}$ alloy, which indicates that atoms in the $\mathrm{Ni}$ intrinsic interlayer are more likely to diffuse into the layer of Fe metal. That is because the concentration gradient of $\mathrm{Ni}$ between the $\mathrm{Ni}$ intrinsic interlayer and the layer of $\mathrm{Fe}$ metal is higher than between the $\mathrm{Ni}$ interlayer and the layer of $\mathrm{FeCr}_{16} \mathrm{Ni}_{10}$ alloy.
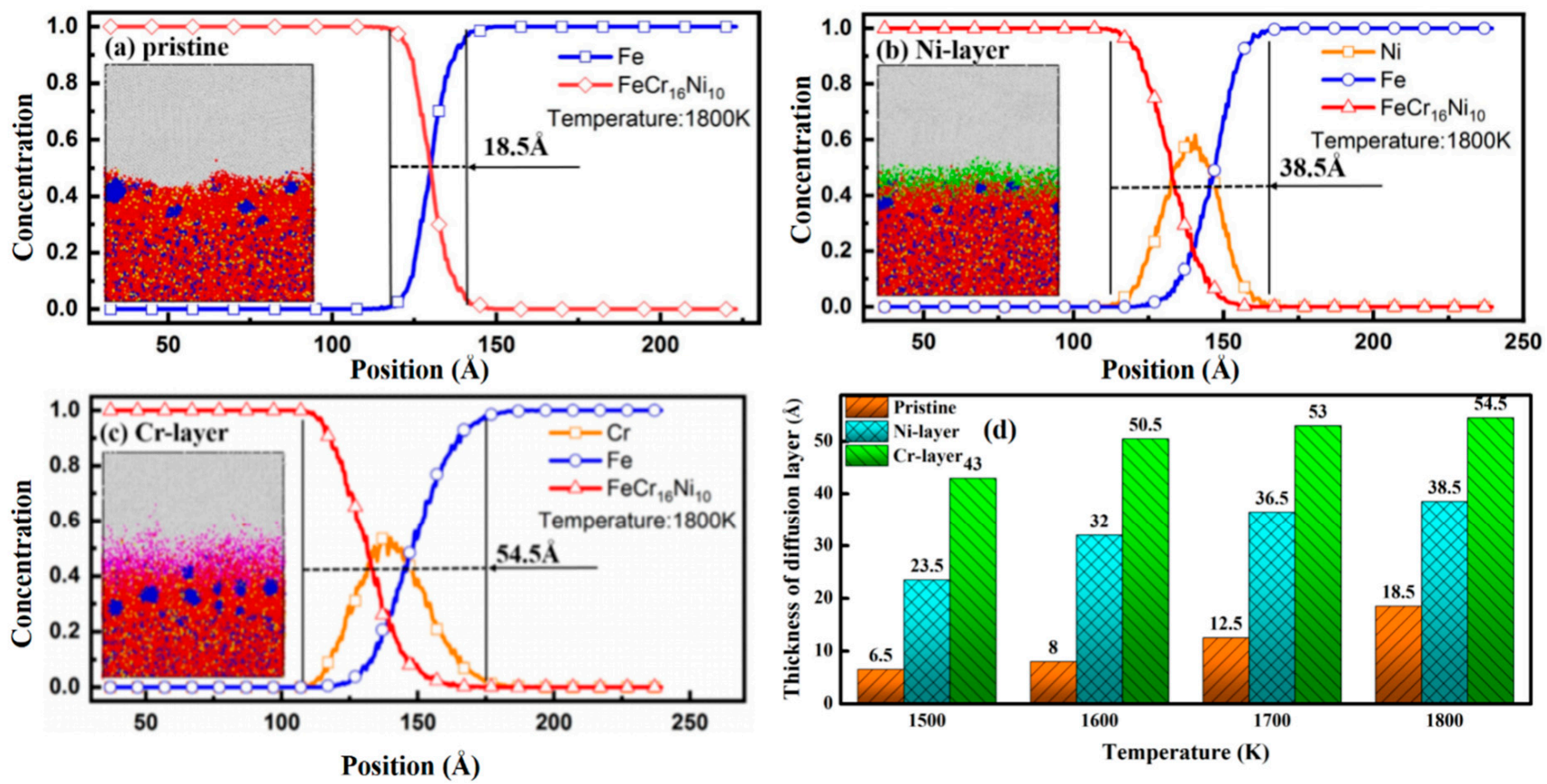

Figure 3. Atomic concentration distributions of $\mathrm{FeCr}_{16} \mathrm{Ni}_{10} / \mathrm{Fe}$ composites with different intrinsic interlayers along the $\mathrm{Z}$ direction at $1800 \mathrm{~K}$ with (a) pristine configuration; (b) Ni-layer; (c) Cr-layer and (d) the thicknesses of the diffusion region.

The thickness of the diffusion region increases by $194.6 \%$ when the $\mathrm{Cr}$ intrinsic interlayer is present, as can be seen from Figure 3c. Obviously, the $\mathrm{Cr}$ intrinsic interlayer also promotes the diffusion and adhesion of $\mathrm{FeCr}_{16} \mathrm{Ni}_{10}$ alloy and $\mathrm{Fe}$ metal. Due to the higher atomic concentration of the $\mathrm{Cr}$ intrinsic interlayer, a higher concentration gradient between the $\mathrm{Cr}$ intrinsic interlayer and the $\mathrm{FeCr}_{16} \mathrm{Ni}_{10}$ alloy (the $\mathrm{Fe}$ metal) will appear, which causes the thickness of the diffusion region between $\mathrm{FeCr}_{16} \mathrm{Ni}_{10}$ alloy and Fe metal to increase. Meanwhile, the effect of the $\mathrm{Cr}$ intrinsic interlayer on the diffusion and adhesion of $\mathrm{FeCr}_{16} \mathrm{Ni}_{10}$ alloy and $\mathrm{Fe}$ metal is much better than the $\mathrm{Ni}$ intrinsic interlayer. This is because the diffusion coefficient of the element of $\mathrm{Cr}$ is larger than the element $\mathrm{Ni}$ and the binding energies of the element of $\mathrm{Cr}$ are smaller than the element of $\mathrm{Ni}$. In previous studies, the diffusivity of $\mathrm{Cr}$ was found to be $6.9745 \times 10^{-10} \mathrm{~m}^{2} \mathrm{~s}^{-1}$ and the diffusivity of $\mathrm{Ni}$ was $6.5144 \times 10^{-10} \mathrm{~m}^{2} \mathrm{~s}^{-1}$ [62]. In addition, similar to the Ni intrinsic interlayer, the atoms in the $\mathrm{Cr}$ intrinsic interlayer diffuse farther towards the layer of Fe metal than towards the layer of $\mathrm{FeCr}_{16} \mathrm{Ni}_{10}$ alloy, which indicates that atoms in $\mathrm{Cr}$ intrinsic interlayer are more likely to diffuse into the layer of $\mathrm{Fe}$ metal. That is because the concentration gradient of $\mathrm{Cr}$ 
between the $\mathrm{Cr}$ intrinsic interlayer and $\mathrm{Fe}$ metal is also higher than between the $\mathrm{Cr}$ intrinsic interlayer and $\mathrm{FeCr}_{16} \mathrm{Ni}_{10}$ alloy.

All in all, the addition of the pure $\mathrm{Ni}$ or $\mathrm{Cr}$ intrinsic interlayer could supply faster diffusion of compositional element and enhance the adhesion of the interface. The effect of the $\mathrm{Cr}$ intrinsic interlayer is much better than the $\mathrm{Ni}$ intrinsic interlayer because the binding energies of the element of $\mathrm{Cr}$ is smaller than that of the element of $\mathrm{Ni}$ and the diffusion coefficient of the element of $\mathrm{Cr}$ is larger than the element of $\mathrm{Ni}$ [72].

The thicknesses of the diffusion region of $\mathrm{FeCr}_{16} \mathrm{Ni}_{10} / \mathrm{Fe}$ composite with different intrinsic interlayers at the temperatures of $1500 \mathrm{~K}, 1600 \mathrm{~K}, 1700 \mathrm{~K}$ and $1800 \mathrm{~K}$ are illustrated in Figure 3d. The thickness of the diffusion region of $\mathrm{FeCr}_{16} \mathrm{Ni}_{10} / \mathrm{Fe}$ composite with pristine configuration is $6.5 \AA$ at the temperature of $1500 \mathrm{~K}$. The thicknesses of the diffusion region of $\mathrm{FeCr}_{16} \mathrm{Ni}_{10} / \mathrm{Fe}$ composite with the addition of the Ni-layer and Cr-layer increase by $261.5 \%$ and $561.5 \%$, respectively. The thickness of the diffusion region of $\mathrm{FeCr}_{16} \mathrm{Ni}_{10} / \mathrm{Fe}$ composite with pristine configuration is $8 \AA$ at a temperature of $1600 \mathrm{~K}$. The thicknesses of the diffusion region of $\mathrm{FeCr}_{16} \mathrm{Ni}_{10} / \mathrm{Fe}$ composite with the addition of Ni-layer and Cr-layer increase by $300 \%$ and $531.3 \%$, respectively. The thickness of the diffusion region of $\mathrm{FeCr}_{16} \mathrm{Ni}_{10} / \mathrm{Fe}$ composite with pristine configuration is $12.5 \AA$ at the temperature of $1700 \mathrm{~K}$. The thicknesses of the diffusion region of $\mathrm{FeCr}_{16} \mathrm{Ni}_{10} / \mathrm{Fe}$ composite with the addition of Nilayer and Cr-layer increase by $192 \%$ and $324 \%$, respectively. The thickness of the diffusion region of $\mathrm{FeCr}_{16} \mathrm{Ni}_{10} / \mathrm{Fe}$ composite with pristine configuration is $18.5 \AA$ at the temperature of $1800 \mathrm{~K}$. The thicknesses of the diffusion region of $\mathrm{FeCr}_{16} \mathrm{Ni}_{10} / \mathrm{Fe}$ composite with the addition of Ni-layer and Cr-layer increase by $108 \%$ and $195 \%$, respectively. Obviously, the addition of the $\mathrm{Ni}$ or the $\mathrm{Cr}$ intrinsic interlayer induces a thicker diffusion region, which leads to enhancement of adhesion. For such enhancement, the $\mathrm{Cr}$ intrinsic interlayer has much better performance than the $\mathrm{Ni}$ intrinsic interlayer.

\subsection{Amorphization Degree of the Interface of the $\mathrm{FeCr}_{16} \mathrm{Ni}_{10} / \mathrm{Fe}$ Composite}

The radius distribution function (RDF) might be used to evaluate the influence of the intrinsic interlayer on the amorphization degree of the interface, by which the atomic spatial distributions and structures near the interface can be characterized. First of all, the region where the diffusion region is thickest is defined as the interface. Secondly the amorphization degree of the interface of $\mathrm{FeCr}_{16} \mathrm{Ni}_{10} / \mathrm{Fe}$ composite with different intrinsic interlayers can be compared by the width and height of the peaks of the RDF curves in the interface. And the broader and lower peak appears, the higher degree of amorphization will be.

The RDFs of the interface of $\mathrm{FeCr}_{16} \mathrm{Ni}_{10} / \mathrm{Fe}$ composite with different intrinsic interlayers at various temperature have been examined, as shown in Figure 4. Similar to liquid, the RDF curves of the interfaces with no intrinsic interlayer all tend rapidly to be united after the second neighbor peak, which indicates short-range order and long-range disorder, from which we can conclude that an amorphous structure has appeared in the interface. This indicates a good agreement between the RDF curves and the previous visualization of atomic structure of the interfaces with no intrinsic interlayer (in Figure 3). However, the $\mathrm{RDF}$ curves of the interfaces with the addition of the $\mathrm{Ni}$ or the $\mathrm{Cr}$ intrinsic interlayer show sharper peaks, which indicates that a more crystalline structure appears. In short, all the above show that the interface structure changes from an amorphous state to a crystalline state when the intrinsic interlayer is present. 

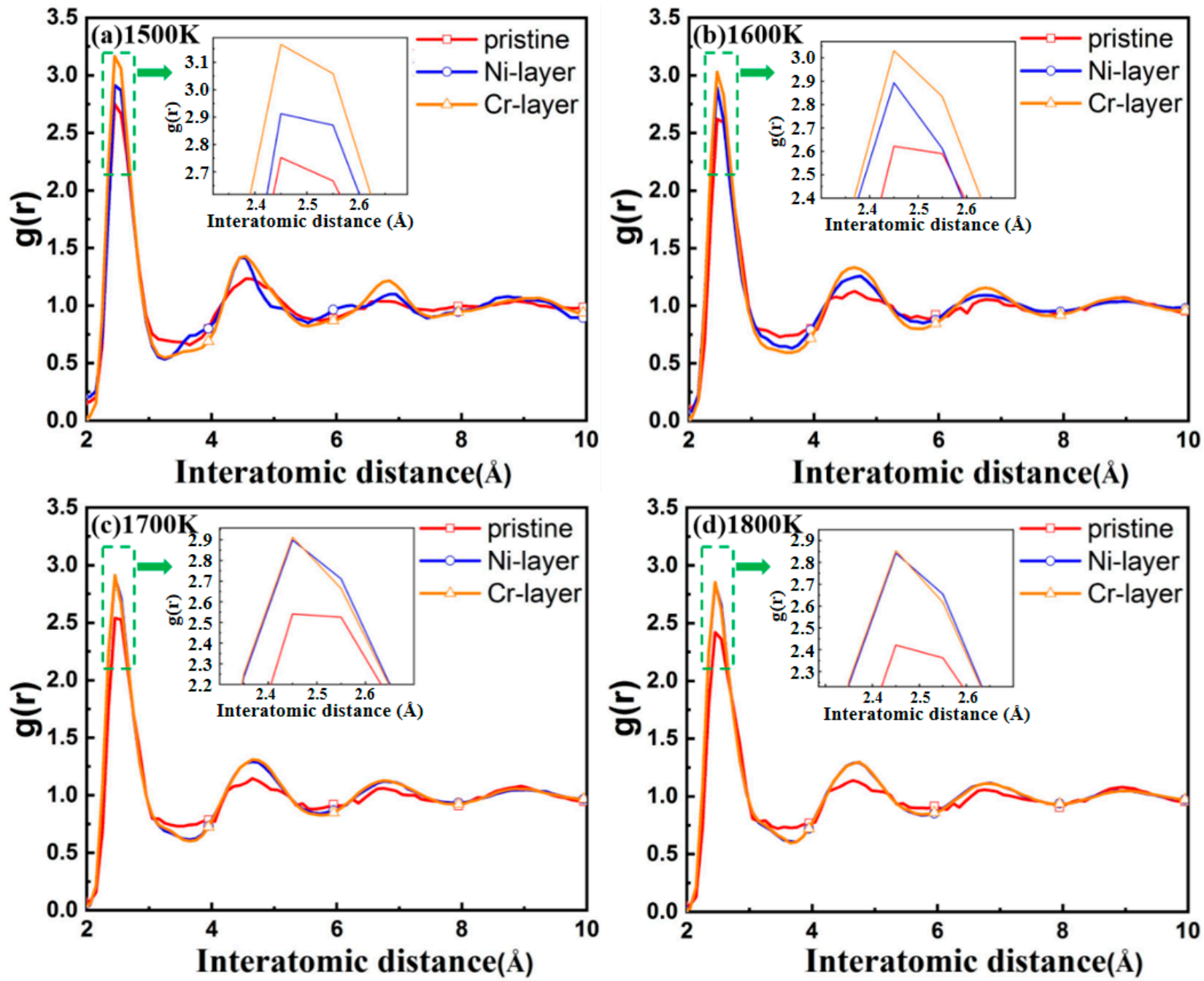

Figure 4. Radius distribution functions of $\mathrm{FeCr}_{16} \mathrm{Ni}_{10} / \mathrm{Fe}$ composites with the different intrinsic interlayers on the interface at different temperatures: (a) $1500 \mathrm{~K}$; (b) $1600 \mathrm{~K}$; (c) $1700 \mathrm{~K}$; (d) $1800 \mathrm{~K}$. The insert images show a first narrower peak appears at the interatomic distance of $2.61 \AA$.

\section{Experimental Analysis}

To validate of our molecular dynamics simulations, we have compared our results to the experimental investigations. Due to the limitation of resources and difficulties of high temperature experiments, including temperature control and corrosion control, the experiments on the thin interlayers are very limited during the hot-rolling process. We only compared and analyze the hot-rolling process with and without $\mathrm{Ni}$ interlayers to check if the interlayer is assisting the bonding.

For the specimen with $\mathrm{FeCr}_{16} \mathrm{Ni}_{10}$ alloy and Fe metal layers, the stainless clad plates with the $\mathrm{Ni}$ intrinsic interlayer and without the $\mathrm{Ni}$ intrinsic interlayer were prepared by the hot rolling process. The microstructure and the diffusion of elements in the interface of the stainless clad plate was studied by using an optical microscope (OM, ZEISS, Jena, Germany) and energy dispersive spectrum (EDS, Thermo Fisher Scientific, Waltham, MA, USA). The experimental materials were 316L stainless steel (composite) and Q345 low carbon steel (substrate). The size of $316 \mathrm{~L}$ stainless steel was $300 \mathrm{~mm} \times 300 \mathrm{~mm} \times 10 \mathrm{~mm}$, and the size of Q345 low carbon steel was $300 \mathrm{~mm} \times 300 \mathrm{~mm} \times 90 \mathrm{~mm}$. The original thickness of the Ni layer was $0.1 \mathrm{~mm}$. The experiment consisted of four steps. First, the surface of the 316L steel and Q345 steel was machined to a certain roughness. Second, the surrounding area was welded and evacuated, and the degree of vacuum was $0.1 \mathrm{~Pa}$. 
Third, the sealed composite slab was heated to $1473 \mathrm{~K}$ for $2 \mathrm{~h}$ and then at this temperature rolled on a two-roll hot rolling mill. The finishing temperature was controlled between $1223 \mathrm{~K}$ and $1323 \mathrm{~K}$. Finally, the hot-rolled sample was polished, and then the carbon steel layer was etched with nital 4 . The distribution of major elements on the two sides of the composite interface were analyzed using an EDS. The microscopic characteristics of the interface were observed using a 200 MAT optical microscope.

In contrast to the reference [73], the macro interface is not a straight line, but a slightly curved curve. The structure of the Q345 steel away from the interface is ferrite and pearlite, and the structure of the Q345 steel from the interface of 150-200 $\mu \mathrm{m}$ is ferrite, which indicates that there is a certain degree of decarburization in this area. Since the carbon in the Q345 steel is easily diffused into the 316L stainless steel under high temperature and deformation conditions, the decarburization occurs on the side of low carbon steel near the composite interface. The experiment of the hot-rolling process with the Ni intrinsic interlayer shows that the decarburization zone on the side of the Q345 steel near the interface is very narrow and less than $50 \mu \mathrm{m}$, which indicates that the diffusion of the element of $\mathrm{C}$ can be significantly prevented by the presence of the Ni intrinsic interlayer [73].

The distributions of the elements like $\mathrm{Cr}$ and $\mathrm{Ni}$ on the two sides of the interface of the composite without the Ni intrinsic interlayer were analyzed by using the EDS, as studied in the reference [73]. The elements such as $\mathrm{Fe}, \mathrm{Cr}$ and $\mathrm{Ni}$ on both sides of the interface vary greatly. The elements such as $\mathrm{Ni}$ and $\mathrm{Cr}$ in the stainless steel (316L) diffuse through the original interface to the low-carbon steel (Q345). The diffusion distance of $\mathrm{Cr}$ is about 20 $\mu \mathrm{m}$ and the diffusion distance of $\mathrm{Ni}$ is about $8 \mu \mathrm{m}$. On one hand, the concentration gradient of the element of $\mathrm{Ni}$ on both sides of the interface is lower than the element of $\mathrm{Cr}$ and on the other, this is because the diffusion coefficient of the element of $\mathrm{Ni}$ is lower than the element of $\mathrm{Cr}$. The distribution of elements such as $\mathrm{Cr}$ and $\mathrm{Ni}$ on the two sides of the interface of the composite with the $\mathrm{Ni}$ intrinsic layer was also analyzed by using the EDS. Compared to the reference [73], the $\mathrm{Cr}$ element in the stainless steel (316L) diffuses into the $\mathrm{Ni}$ intrinsic interlayer, which causes a decrease in the $\mathrm{Cr}$ content. And the elements of Fe in the stainless steel (316L) and the low-carbon steel (Q345R) diffuse into the Ni intrinsic interlayer, while the elements of $\mathrm{Ni}$ in the Ni intrinsic interlayer diffuse into both sides of the interface. The diffusion distances of the element of $\mathrm{Ni}$ both between the $\mathrm{Ni}$ intrinsic interlayer and the layer of the low-carbon steel (Q345R) and between the Ni intrinsic interlayer and the layer of the stainless steel (316L) are $25 \mu \mathrm{m}$ and $20 \mu \mathrm{m}$, respectively. The reason the diffusion distance of the element of $\mathrm{Ni}$ between $\mathrm{Ni}$ intrinsic interlayer and the low-carbon steel (Q345R) is longer than between the $\mathrm{Ni}$ intrinsic interlayer and the layer of stainless steel $(316 \mathrm{~L})$ is that the concentration gradient of the element of Ni between the $\mathrm{Ni}$ intrinsic interlayer and the low-carbon steel is bigger than between the $\mathrm{Ni}$ intrinsic interlayer and the stainless steel. This is consistent with the previous visualization of atomic structure in Figure $3 \mathrm{~b}$. The Ni elements in the Ni intrinsic interlayer asymmetrically diffuse to both sides of the interface and proceed with diffusion. This results in the concentration gradients between the Ni intrinsic interlayer and both sides reducing and gradually slowing down. Compared to the diffusion region of the hot rolled sheets with and without the Ni intrinsic interlayer by the EDS analysis, the thickness increases when the $\mathrm{Ni}$ intrinsic interlayer is present. Due to the higher atomic concentration of the Ni intrinsic interlayer, a higher concentration gradient between the $\mathrm{Ni}$ intermediate layer and the stainless steel (316L) (the low-carbon steel (Q345R)) makes the thickness of the diffusion region increase.

\section{Conclusions}

To study the influence of the intrinsic interlayers on the diffusion assisted bonding properties of the austenitic steel and ferric steels in a hot rolling process, the molecular dynamics simulation and experiment have been used in this work. Our research reveals the effect of the intrinsic interlayer on the bonding process in order to provide a theoretical basis for optimizing the manufacturing process of the hot rolled sheet. The main conclusions are as follows: 
(1) Through molecular dynamics simulation, we found that the addition of the intrinsic interlayer can reduce the maximum stress between the austenitic steel and carbon steel during the hot rolling process and is conducive to the bonding of the austenitic steel and carbon steel. In addition, the intrinsic inter-layer improves the adhesion of the austenitic steel and carbon steel and makes the diffusion region thicker. The effect of the $\mathrm{Cr}$ intrinsic interlayer is superior to the $\mathrm{Ni}$ intrinsic interlayer.

(2) Experimental investigation shows that the thickness of the diffusion region between the stainless steel (316L) and the low-carbon steel (Q345R) increases when the intrinsic interlayer is present. And the atoms in intrinsic interlayer diffuse farther towards the carbon steel than the austenitic steel, which indicates that atoms in the intrinsic interlayer are more likely to diffuse into the carbon steel.

Supplementary Materials: The following are available online at https:/ /www.mdpi.com/article/10 $.3390 / \mathrm{ma14092416/s1}$, Figure S1. Atomic concentration distributions of the $\mathrm{FeCr}_{16} \mathrm{Ni}_{10} / \mathrm{Fe}$ composite with different intrinsic interlayers along the $Z$ direction at $1500 \mathrm{~K}$ with (a) pristine configuration; (b) Ni-layer; (c) Cr-layer; Figure S2. Atomic concentration distributions of $\mathrm{FeCr}_{16} \mathrm{Ni}_{10} / \mathrm{Fe}$ composites with different intrinsic interlayers along the $Z$ direction at $1600 \mathrm{~K}$ with (a) pristine configuration; (b) Ni-layer; (c) Cr-layer; Figure S3. Atomic concentration distributions of $\mathrm{FeCr}_{16} \mathrm{Ni}_{10} / \mathrm{Fe}$ composites with different intrinsic interlayers along the $Z$ direction at $1700 \mathrm{~K}$ with (a) pristine configuration; (b) Ni-layer; (c) Cr-layer; Table S1. The Elements Composition of Materials (\%).

Author Contributions: Conceptualization, L.X. and Q.P.; methodology, C.H.; software, C.H.; validation, L.X., G.P. and Q.P.; formal analysis, C.H.; investigation, Q.P.; resources, C.H.; data curation, C.H.; writing—original draft preparation, C.H.; writing—review and editing, L.X. and Q.P.; visualization, G.P.; supervision, Q.P.; project administration, L.X.; funding acquisition, L.X. All authors have read and agreed to the published version of the manuscript.

Funding: This work was supported by the National Key R\&D Program of China (Grant No. 2020YFA0405700) and the Fundamental Research Funds for the Central Universities (Grant No. FRF-MP-20-31). Q.P. would like to acknowledge the support provided by the Deanship of Scientific Research (DSR) at King Fahd University of Petroleum \& Minerals (KFUPM) through project No. DF201020.

Institutional Review Board Statement: Not applicable.

Informed Consent Statement: Not applicable.

Data Availability Statement: The data presented in this study are available on request from the corresponding author.

Conflicts of Interest: The authors declare that they have no known competing financial interests or personal relationships that could have appeared to influence the work reported in this paper.

\section{References}

1. Mousavi, S.A.; Sartangi, P.F. Effect of post-weld heat treatment on the interface microstructure of explosively welded titaniumstainless steel composite. Mater. Sci. Eng. A 2008, 494, 329-336. [CrossRef]

2. Orhan, N.; Khan, T.; Eroğlu, M.J.S.M. Diffusion bonding of a microduplex stainless steel to Ti-6Al-4V. Scr. Mater. 2001, 45, 441-446. [CrossRef]

3. Ghosh, M.; Chatterjee, S. Characterization of transition joints of commercially pure titanium to 304 stainless steel. Mater. Charact. 2002, 48, 393-399. [CrossRef]

4. Ghosh, M.; Bhanumurthy, K.; Kale, G.; Krishnan, J.; Chatterjee, S. Diffusion bonding of titanium to 304 stainless steel. J. Nucl. Mater. 2003, 322, 235-241. [CrossRef]

5. Ghosh, M.; Chatterjee, S. Diffusion bonded transition joints of titanium to stainless steel with improved properties. Mater. Sci. Eng. A 2003, 358, 152-158. [CrossRef]

6. Sabetghadam, H.; Hanzaki, A.Z.; Araee, A.; Hadian, A. Microstructural evaluation of 410 SS/Cu diffusion-bonded joint. J. Mater. Sci. Technol. 2010, 26, 163-169. [CrossRef]

7. Yilmaz, O.; Aksoy, M. Investigation of micro-crack occurrence conditions in diffusion bonded Cu-304 stainless steel couple. J. Mater. Process. Technol. 2002, 121, 136-142. [CrossRef]

8. Zhang, H.; Chen, Y.; Luo, A.A. A novel aluminum surface treatment for improved bonding in magnesium/aluminum bimetallic castings. Scr. Mater. 2014, 86, 52-55. [CrossRef] 
9. Feng, Y.-Y.; Yu, H.; Luo, Z.-A.; Xie, G.-M.; Misra, R. The impact of surface treatment and degree of vacuum on the interface and mechanical properties of stainless steel clad plate. Materials 2018, 11, 1489. [CrossRef]

10. Nicholas, M.G.; Crispin, R.M. Diffusion bonding stainless steel to alumina using aluminium interlayers. J. Mater. Sci. 1982, 17, 3347-3360. [CrossRef]

11. Elrefaey, A.; Tillmann, W. Solid state diffusion bonding of titanium to steel using a copper base alloy as interlayer. J. Mater. Process. Technol. 2009, 209, 2746-2752. [CrossRef]

12. Li, G.; Jiang, W.; Fan, Z.; Jiang, Z.; Liu, X.; Liu, F. Effects of pouring temperature on microstructure, mechanical properties, and fracture behavior of $\mathrm{Al} / \mathrm{Mg}$ bimetallic composites produced by lost foam casting process. Int. J. Adv. Manuf. Technol. 2017, 91, 1355-1368. [CrossRef]

13. Weng, S.; Ning, H.; Fu, T.; Hu, N.; Zhao, Y.; Huang, C.; Peng, X. Molecular dynamics study of strengthening mechanism of nan-olaminated graphene/Cu composites under compression. Sci. Rep. 2018, 8, 3089. [CrossRef]

14. Zhang, J.; Xiao, Y.; Luo, G.; Shen, Q.; Zhang, L. Effect of Ni interlayer on strength and microstructure of diffusion-bonded Mo/Cu joints. Mater. Lett. 2012, 66, 113-116. [CrossRef]

15. Fukumoto, S.; Inoue, T.; Mizuno, S.; Okita, K.; Tomita, T.; Yamamoto, A. Friction welding of TiNi alloy to stainless steel using Ni interlayer. Sci. Technol. Weld. Join. 2010, 15, 124-130. [CrossRef]

16. Qi, X.; Song, G. Interfacial structure of the joints between magnesium alloy and mild steel with nickel as interlayer by hybrid laser-TIG welding. Mater. Des. 2010, 31, 605-609. [CrossRef]

17. Yuan, J.; Gupta, V. Gupta, The effect of microstructure and chemistry on the tensile strength of Nb/sapphire interfaces with and without interlayers of Sb and Cr. Acta Metall. Mater. 1995, 43, 781-794. [CrossRef]

18. Kock, T.; Brendel, A.; Bolt, H. Interface reactions between silicon carbide and interlayers in silicon carbide-copper metal-matrix composites. J. Nucl. Mater. 2007, 362, 197-201. [CrossRef]

19. Jiangwei, R.; Yajiang, L.; Tao, F. Microstructure characteristics in the interface zone of Ti/Al diffusion bonding. Mater. Lett. 2002, 56, 647-652. [CrossRef]

20. Jiang, W.; Fan, Z.; Li, C. Improved steel/aluminum bonding in bimetallic castings by a compound casting process. J. Mater. Process. Technol. 2015, 226, 25-31. [CrossRef]

21. Jiang, W.; Jiang, Z.; Li, G.; Wu, Y.; Fan, Z. Microstructure of Al/Al bimetallic composites by lost foam casting with Zn interlayer. Mater. Sci. Technol. 2017, 34, 487-492. [CrossRef]

22. Elices, M.; Guinea, G.; Gómez, J.; Planas, J. The cohesive zone model: Advantages, limitations and challenges. Eng. Fract. Mech. 2002, 69, 137-163. [CrossRef]

23. Camanho, P.P.; Dávila, C.G. Mixed-Mode Decohesion Finite Elements for the Simulation of Delamination in Composite Materials; NASA Center for AeroSpace Information (CASI): Hanover, MD, USA, 2002.

24. Yang, Q.; Cox, B. Cohesive models for damage evolution in laminated composites. Int. J. Fract. 2005, 133, 107-137. [CrossRef]

25. Li, Z.; Zhao, J.; Jia, F.; Zhang, Q.; Liang, X.; Jiao, S.; Jiang, Z. Analysis of bending characteristics of bimetal steel composite. Int. J. Mech. Sci. 2018, 148, 272-283. [CrossRef]

26. Schnabl, S.; Planinc, I. Three-dimensional bimetallic layered beams with interface compliance: Analytical solution. Proc. Inst. Mech. Eng. Part L J. Mater. Des. Appl. 2018, 233, 358-371. [CrossRef]

27. Lee, H.S. Diffusion bonding of metal alloys in aerospace and other applications. In Welding and Joining of Aerospace Materials; Woodhead Publishing: Cambridge, UK, 2021; pp. 320-344.

28. Ding, W.; Liu, N.; Fan, J.; Cao, J.; Wang, X. Diffusion bonding of copper to titanium using CoCrFeMnNi high-entropy alloy in-terlayer. Intermetallics 2021, 129, 107027. [CrossRef]

29. Liu, Y.; Luo, Y.; Zhao, D.; Zhang, G.; Kang, L. Interfacial behavior and joint performance of high-entropy alloy CoCrFeMnNi and pure cu joints obtained by vacuum diffusion welding. J. Mech. Eng. 2017, 53, 84-91. [CrossRef]

30. Negemiya, A.A.; Rajakumar, S.; Balasubramanian, V.; Arulsamy, A.N.; Selvarajan, R.; Visvalingam, B. Influence of high temperature diffusion bonding process parameters on mechanical and metallurgical characteristics of nickel superalloy to martensitic stainless steel. Microsc. Res. Tech. 2019, 83, 318-328. [CrossRef]

31. Bringa, E.M.; Caro, A.; Wang, Y.; Victoria, M.; McNaney, J.M.; Remington, B.A.; Smith, R.F.; Torralva, B.R.; Van Swygenhoven, H. Ultrahigh strength in nanocrystalline materials under shock loading. Science 2005, 309, 1838-1841. [CrossRef]

32. Heino, P.; Hakkinen, H.; Kaski, K. Molecular-dynamics study of mechanical properties of copper. Europhys. Lett. 1998, 41, 273-278. [CrossRef]

33. Peng, Q.; Meng, F.; Yang, Y.; Lu, C.; Deng, H.; Wang, L.; De, S.; Gao, F. Shockwave generates < $100>$ dislocation loops in bcc iron. Nat. Commun. 2018, 9, 1-6. [CrossRef]

34. Xie, L.; An, H.; Peng, Q.; Qin, Q.; Zhang, Y. Sensitive five-fold local symmetry to kinetic energy of depositing atoms in Cu-Zr thin film growth. Materials 2018, 11, 2548. [CrossRef]

35. Xie, L.; An, H.; He, C.; Qin, Q.; Peng, Q. Mechanical properties of vacancy tuned carbon honeycomb. Nanomaterials 2019, 9, 156. [CrossRef]

36. Qin, Q.; An, H.; He, C.; Xie, L.; Peng, Q. Anisotropic and temperature dependent mechanical properties of carbon honeycomb. Nanotechnology 2019, 30, 325704. [CrossRef]

37. Xie, L.; Sun, T.; He, C.; An, H.; Qin, Q.; Peng, Q. Effect of angle, temperature and vacancy defects on mechanical properties of psi-graphene. Crystals 2019, 9, 238. [CrossRef] 
38. Hou, J.; Deng, B.; Zhu, H.; Lan, Y.; Shi, Y.; De, S.; Liu, L.; Chakraborty, P.; Gao, F.; Peng, Q. Magic auxeticity angle of graphene. Carbon 2019, 149, 350-354. [CrossRef]

39. Lu, K.; Huo, C.-F.; He, Y.; Guo, W.-P.; Peng, Q.; Yang, Y.; Li, Y.-W.; Wen, X.-D. The structure-activity relationship of Fe nanoparticles in CO adsorption and dissociation by reactive molecular dynamics simulations. J. Catal. 2019, 374, 150-160. [CrossRef]

40. Derlet, P.; Van Swygenhoven, H. Length scale effects in the simulation of deformation properties of nanocrystalline metals. Scr. Mater. 2002, 47, 719-724. [CrossRef]

41. Schiøtz, J.; Jacobsen, K.W. A maximum in the strength of nanocrystalline copper. Science 2003, 301, 1357-1359. [CrossRef] [PubMed]

42. Brandl, C.; Derlet, P.M.; Van Swygenhoven, H. Strain rates in molecular dynamics simulations of nanocrystalline metals. Philos. Mag. 2009, 89, 3465-3475. [CrossRef]

43. Li, X.; Wei, Y.; Lu, L.; Lu, K.; Gao, H. Dislocation nucleation governed softening and maximum strength in nano-twinned metals. Nat. Cell Biol. 2010, 464, 877-880. [CrossRef] [PubMed]

44. Peng, Q.; Zhang, X.; Lu, G. Structure, mechanical and thermodynamic stability of vacancy clusters in Cu. Model. Simul. Mater. Sci. Eng. 2010, 18. [CrossRef]

45. Huang, C.; Peng, X.; Fu, T.; Chen, X.; Xiang, H.; Li, Q.; Hu, N. Molecular dynamics simulation of BCC Ta with coherent twin boundaries under nanoindentation. Mater. Sci. Eng. A 2017, 700, 609-616. [CrossRef]

46. Chen, S.; Soh, A.; Ke, F. Molecular dynamics modeling of diffusion bonding. Scr. Mater. 2005, 52, 1135-1140. [CrossRef]

47. Lee, S.-G.; Kim, S.-P.; Lee, K.-R.; Chung, Y.-C. Atomic-level investigation of interface structure in Ni-Al multilayer system: Mo-lecular dynamics simulation. J. Magn. Magn. Mater. 2005, 286, 394-398. [CrossRef]

48. Li, Z.; Zhao, L.; Guo, Q.; Li, Z.; Fan, G.; Guo, C.; Zhang, D. Enhanced dislocation obstruction in nanolaminated graphene/Cu composite as revealed by stress relaxation experiments. Scr. Mater. 2017, 131, 67-71. [CrossRef]

49. Yan, Y.; Zhou, S.; Liu, S. Atomistic simulation on nanomechanical response of indented graphene/nickel system. Comput. Mater. Sci. 2017, 130, 16-20. [CrossRef]

50. Fu, T.; Peng, X.; Chen, X.; Weng, S.; Hu, N.; Li, Q.; Wang, Z. Molecular dynamics simulation of nanoindentation on Cu/Ni nanotwinned multilayer films using a spherical indenter. Sci. Rep. 2016, 6, 35665. [CrossRef]

51. Huang, H.; Tang, X.; Gao, F.; Chen, F.; Ge, G.; Yan, Y.; Peng, Q. Release of helium-related clusters through a nickel-graphene interface: An atomistic study. Appl. Surf. Sci. 2019, 487, 218-227. [CrossRef]

52. Kim, Y.-K.; Jung, W.-S.; Lee, B.-J. Modified embedded-atom method interatomic potentials for the Ni-Co binary and the Ni-Al-Co ternary systems. Model. Simul. Mater. Sci. Eng. 2015, 23, 055004. [CrossRef]

53. Wu, C.; Lee, B.-J.; Su, X. Modified embedded-atom interatomic potential for Fe-Ni, Cr-Ni and Fe-Cr-Ni systems. Calphad 2017, 57, 98-106. [CrossRef]

54. Spearot, D.E.; Tschopp, M.A.; Jacob, K.I.; McDowell, D.L. Tensile strength of $\langle 100\rangle$ and $\langle 110\rangle$ tilt bicrystal copper interfaces. Acta Mater. 2007, 55, 705-714. [CrossRef]

55. Weissmann, M.; Ramírez, R.; Kiwi, M. Molecular-dynamics model of interface amorphization. Phys. Rev. B 1992, 46, 2577-2583. [CrossRef] [PubMed]

56. Chen, S.Y.; Wu, Z.W.; Liu, K.X.; Li, X.J.; Luo, N.; Lu, G.X. Atomic diffusion behavior in Cu-Al explosive welding process. J. Appl. Phys. 2013, 113, 044901. [CrossRef]

57. Chen, X.; Kong, X.; Misra, A.; Legut, D.; Yao, B.; Germann, T.; Zhang, R. Effect of dynamic evolution of misfit dislocation pattern on dislocation nucleation and shear sliding at semi-coherent bimetal interfaces. Acta Mater. 2018, 143, 107-120. [CrossRef]

58. Bonny, G.; Terentyev, D.; Pasianot, R.C.; Poncé, S.; Bakaev, A. Interatomic potential to study plasticity in stainless steels: The FeNiCr model alloy. Model. Simul. Mater. Sci. Eng. 2011, 19, 085008. [CrossRef]

59. Bonny, G.; Castin, N.; Terentyev, D. Interatomic potential for studying ageing under irradiation in stainless steels: The FeNiCr model alloy. Model. Simul. Mater. Sci. Eng. 2013, 21, 085004. [CrossRef]

60. Plimpton, S. Fast parallel algorithms for short-range molecular dynamics. J. Comput. Phys. 1995, 117, 1-19. [CrossRef]

61. Stukowski, A. Structure identification methods for atomistic simulations of crystalline materials. Model. Simul. Mater. Sci. Eng. 2012, 20, 045021. [CrossRef]

62. Verlet, L. Computer experiments on classical fluids. i Thermodinamical properties of Lennard-Jones molecules. Phys. Rev. 1967, 159, 98. [CrossRef]

63. Hoover, W.G. Canonical dynamics: Equilibrium phase-space distributions. Phys. Rev. A 1985, 31, 1695-1697. [CrossRef]

64. Hoover, W.G. Constant-pressure equations of motion. Phys. Rev. A 1986, 34, 2499-2500. [CrossRef] [PubMed]

65. Chen, S.; Ke, F.; Zhou, M.; Bai, Y. Atomistic investigation of the effects of temperature and surface roughness on diffusion bonding between $\mathrm{Cu}$ and Al. Acta Mater. 2007, 55, 3169-3175. [CrossRef]

66. Qin, Q.; He, W.; Xie, L.; Deng, J.; Zhu, X.; Peng, Q. Nonlinear diffusion, bonding, and mechanics of the interface between austenitic steel and iron. Phys. Chem. Chem. Phys. 2018, 21, 1464-1470. [CrossRef] [PubMed]

67. Mastorakos, I.N.; Zbib, H.M.; Bahr, D.F. Deformation mechanisms and strength in nanoscale multilayer metallic composites with coherent and incoherent interfaces. Appl. Phys. Lett. 2009, 94, 173114. [CrossRef]

68. Hoagland, R.G.; Mitchell, T.E.; Hirth, J.P.; Kung, H. On the strengthening effects of interfaces in multilayer fee metallic composites. Philos. Mag. A 2002, 82, 643-664. [CrossRef] 
69. Khomyakov, P.A.; Giovannetti, G.; Rusu, P.C.; Brocks, G.; Brink, J.V.D.; Kelly, P.J. First-principles study of the interaction and charge transfer between graphene and metals. Phys. Rev. B 2009, 79, 195425. [CrossRef]

70. Sabetghadam, H.; Hanzaki, A.Z.; Araee, A. Diffusion bonding of 410 stainless steel to copper using a nickel interlayer. Mater. Charact. 2010, 61, 626-634. [CrossRef]

71. Zhong, Z.; Jung, H.-C.; Hinoki, T.; Kohyama, A. Effect of joining temperature on the microstructure and strength of tungsten/ferritic steel joints diffusion bonded with a nickel interlayer. J. Mater. Process. Technol. 2010, 210, 1805-1810. [CrossRef]

72. Johll, H.; Kang, H.C.; Tok, E.S. Density functional theory study of Fe, Co, and Ni adatoms and dimers adsorbed on graphene. Phys. Rev. B 2009, 79, 245416. [CrossRef]

73. Long, L.I.; Zhang, X.J.; Gang, L.; Huan-Yu, F.U.; Meng-Nie, L.I. Effect of Ni layer thickness on bonding strength of hot rolled clad steel plate. Trans. Mater. Heat Treat. 2015, 36, 80-85. 